\title{
Economic Impact of Sunitinib and Sorafenib Use in Metastatic Renal Cell Carcinoma Treatment in Veneto Region, Italy
}

\author{
Simonetta Ballali ${ }^{1}$, Daniele Chiffi ${ }^{2}$, Marta P. Trojniak ${ }^{3}$, Dario Gregori ${ }^{*}, 2$ and the \\ EIHCD-VeRo Research Project Agreement ${ }^{\S}$
}

${ }^{I}$ Prochild Onlus, Trieste, Italy \& Unit of Biostatistics, Epidemiology and Public Health, Department of Cardiac, Thoracic and Vascular Sciences, University of Padova, Padova, Italy

${ }^{2}$ Unit of Biostatistics, Epidemiology and Public Health, Department of Cardiac, Thoracic and Vascular Sciences, University of Padova, Padova, Italy

${ }^{3}$ Oncology Pharmacy Department, Istituto Oncologico Veneto, IRCCS, Padova, Italy

\begin{abstract}
Objective: To evaluate the impact of multitargeted tyrosine kinase inhibitors (TKI) considering $1^{\text {st }}$ and $2^{\text {nd }}$ line treatment for a full period of 3 years in the eligible patients of Veneto Region.

Methods: A Markov state decision model was selected to evaluate the cost impact of sunitinib and sorafenib use for a lapse of time of three years in Veneto public hospitals, considering transition probabilities from three different states and by comparing the expected deaths and the monthly survival rates in treatment and no-treatment groups.

Results: From the initial cohort of 357 patients eligible for sunitinib treatment, stable ones (139) were considered in order to evaluate the impact of the multitargeted agent on overall progression of the disease. Results showed that a smaller portion of patients receiving sunitinib transited from a stable to a progressive state, with respect to the patients who were not receiving sunitinib. The cost of 6 months treatment with sunitinib reached a median value of $2532666 €$, increasing till $3607807 €$ as cumulative amount at 12 months. Costs after the $1^{\text {st }}$ year flattened around the same figure (3800000€) due to the transition towards death or $2^{\text {nd }}$ line treatments.

Discussion: the costs of the first 6 months therapy with sunitinib have a very high impact on public health expenses in the Regione Veneto. $2^{\text {nd }}$ line treatment with sorafenib instead increased overall expenses of a reduced proportion, due to the small proportion of patients undergoing this treatment and the relative inferior cost of the drug.

Conclusion: From what came out from our simulated model on costs borne by the SSN for the treatment of patients with mRCC, we can conclude that they are effective on the progression of the disease the greatest impact being the cost for the $1^{\text {st }}$ line pharmacological treatment.
\end{abstract}

Keywords: Cost, metastasis, renal cell cancer, sorafenib, sunitinib, Veneto.

\begin{abstract}
*Address correspondence to this author at the Unit of Biostatistics, Epidemiology and Public Health, Department of Cardiac, Thoracic and Vascular Sciences, Via Loredan 18, 35121 Padova, Italy; Tel: +39 049 8275384; Fax: +3902 700445089; E-mail: dario.gregori@unipd.it
\end{abstract}

${ }^{\S}$ EIHCD-VeRo (Economic Impact of High Cost Drugs in the Veneto Region) Research Project Agreement members: Dario Gregori (Principal Investigator), Unit of Biostatistics, Epidemiology and Public Health, Department of Cardiac, Thoracic and Vascular Sciences, University of Padova, Padova, Italy; Daniele Chiffi, Unit of Biostatistics, Epidemiology and Public Health, Department of Cardiac, Thoracic and Vascular Sciences, University of Padova, Padova, Italy; Francesco Grigoletto, Department of Environmental Medicine and Public Health, University of Padova, Italy; Egle Perissinotto, Unit of Biostatistics, Epidemiology and Public Health, Department of Cardiac, Thoracic and Vascular Sciences, University of Padova, Padova, Italy; Alessandra Buja, Department of Molecular Medicine, University of Padova, Italy; Andrea Tramarina, Veneto Regional Health Agency, Italy; Costantino Gallo, Veneto Regional Health Agency, Italy; Antonio Compostella, Veneto Regional Health Agency, Italy; Davide Pastorelli, Istituto Oncologico del Veneto IRCSS, Padova, Italy; Giuseppe Rausa, Department of Environmental Medicine and Public Health, University of Padova, Italy.

\section{INTRODUCTION}

Worldwide, kidney cancer is the 13th most common malignancy, with approximately 271000 new cases diagnosed in 2008 [1]. There are significant geographical variations on the incidence of kidney cancer: the highest rates can be seen in Europe, North America, and Australia, while rates in India, Japan, Africa, and China are lower ones. In Italy, from the start of the late 1980's, mortality from kidney cancer has been decreasing in both sexes (from 4.2 to $3.8 / 100,000$ in men and from $1.6 / 100,000$ to 1.4 in women between the early 1990's and the early 2000's) [2]. Kidney cancer, whose definition includes also cancers of the renal pelvis, ureter, and urethra, represented $3.2 \%$ of all the cancer diagnoses among males and 2.1\% among females from 1998 till $2002[3,4]$ of which about $85 \%$ were from parenchymal or renal cell cancer (RCC). In the Italian report of 2010 on tumors prevalence, kidney cancer was the 8th most common cancer, with 84413 people living with cancer, of which 8397 
were estimated to live in Veneto. In a ranking of cancer prevalence, kidney and urinary tract cancers rank sixth place in males and tenth in females [3]. The most reliable estimate of incident kidney cancer cases in Italy in the period 20072012 is expected to range between 7000 and 9000, of whom between 6000 and 8000 are RCC cases [5]. RCC accounts for approximately $90 \%$ of all renal malignancies and for about $3 \%$ of all human malignancies [6]. Regardless the advances in diagnosis, almost $30 \%$ of all patients are diagnosed with metastatic disease [7]. Management of metastatic RCC (mRCC) has improved in the last ten years due to a better understanding of the molecular pathogenesis of RCC and the development of targeted therapies. Before the introduction of molecular targeted therapies in 2005, fewer than $10 \%$ of patients with $\mathrm{mRCC}$ survived beyond 5 years and response rates ranged from 10 to $35 \%$ [8]. Six targeted agents have been approved to treat advanced RCC since 2005. Sorafenib, sunitinib, pazopanib and bevacizumab target the Vascular Endothelial Growth Factor (VEGF) pathway, and temsirolimus and everolimus inhibit the mammalian target of rapamycin (mTOR) pathway. For patients with previously untreated RCC, sunitinib is the reference standard, while sorafenib is recommended for second line therapy, after cytokine's prior therapy [9]. Like other molecular targeted therapies, sunitinib and sorafenib fall into the category of high-costs drugs, whose costs are totally covered in Italy by public hospitals budget.

This paper aims at assessing the public impact of the use of sunitinib and sorafenib in first and second line treatment in patients with $\mathrm{mRCC}$ afferents to public hospitals of Veneto region in Italy.

\section{MATERIALS AND METHODS}

\section{Targeted Therapy}

Sunitinib malate, here mentioned simply as sunitinib, is a small-molecule inhibitor of tyrosine kinases receptor (TKR) involved in tumor proliferation and angiogenesis, which is used as first line treatment in mRCC [10]. Two of the most important receptors are platelet-derived growth factor receptor (PDGFR) and vascular endothelial growth factor receptor (VEGFR). Sunitinib acts by inhibiting phosphorylation of multiple specific intracellular tyrosine kinase receptors [11]. The recommended dose of sunitinib is one $50 \mathrm{mg} /$ daily dose orally taken for four consecutive weeks with a two week rest period i.e. a complete treatment cycle of six weeks [12].

Sorafenib tosylate, here referred to as sorafenib, is an orally administered bi-aryl urea that inhibits various tyrosine kinase receptors including VEGFR and PDGFR [13]. Sorafenib may also inhibit Raf-1 [14], a member of the mitogen-activated protein kinase (MAPK) intracellular signal transduction pathway, used in individuals who are not suitable for treatment with IFN and as second line therapy in those, treatment with cytokine based immunotherapy has failed. The recommended dose of sorafenib is $400 \mathrm{mg}$ twice daily, taken either one hour before or two hours after food [15].

Specific data on drugs characteristics and administration are reported in Table $\mathbf{1}$.
Table 1. Characteristics of Multi-Targeted Agents Used in Metastatic Renal Cell Cancer (BW, Body Weight; BS, Body Surface)

\begin{tabular}{|c|c|c|}
\hline & Sunitinib & Sorafenib \\
\hline \hline Trade name & Sutent & Nevaxar \\
\hline Selling dosage & $50 \mathrm{mg} / 25 \mathrm{mg} / 12,5 \mathrm{mg}$ & $200 \mathrm{mg}$ \\
\hline Administration & oral & oral \\
\hline Line of treatment & $1 \mathrm{st}$ & $2 \mathrm{nd}$ \\
\hline Frequency of single cycle & $\begin{array}{c}4 \text { weeks of treatment and } \\
\text { of pause }(4 / 2 \text { scheme })\end{array}$ & Daily \\
\hline Dose Target Agent & $50 \mathrm{mg} /$ die & $800 \mathrm{mg} /$ die \\
\hline
\end{tabular}

\section{Setting}

Veneto is an Italian region with a population of 4.8 million and is situated in Northeast Italy. It has a population of 4937854 (year 2010) [16] and the incidence of new cases of renal cell carcinoma in Veneto is more than 2000 cases per year [17].

\section{Target Population}

The determination of the target population for sunitinib is obtained by taking into account the annual incidence of $\mathrm{mRCC}$, considering metastatic cases at diagnosis and yearly probabilities of progression from non-metastatic cases to metastatic cases. Target population of sorafenib administration is calculated considering the yearly probabilities to be IFN $\alpha$ or IL 2 therapies refractory, therefore undergoing to a second line therapy. All data were obtained from published literature, institutional-derived data from the pharmacological database of IOV (Istituto Oncologico Veneto) [17] and Sistar (Veneto Region Statistical System) [16]. Data were divided into three categories, patients undergoing sunitinib treatment (sunitinib + ), patients not receiving sunitinib treatment (sunitinib -), patients receiving sorafenib as second line therapy (sorafenib + ). All data are presented in Tables 2-4.

Eligible to receive sunitinib were considered all patients stable at the time of administration. Patients that were undergoing a transition from the stable condition to a progressive state over the fixed time interval of 6 months were identified as targets for 2nd and 3rd line therapy. Prevalence of each Markov's state was evaluated at month 6, $12,18,24,30$ and 36 .

\section{Markov Decision Model}

A Markov state decision model was selected to evaluate the cost impact of sunitinib and sorafenib use for a lapse of time of three years in Veneto public hospitals considering transition probabilities from three different states, and by comparing the expected deaths and the monthly survival rates in treatment and no-treatment groups (Fig. 1). This indicator has already been proven to be valid tool to for costs considerations [18]. The transition probabilities for clinical variables are shown in Tables 2 and 3. Markov Model consists of 3 different states: "Stable disease", "Progressive 
Table 2. Incidences and Probabilities of Transition Among Markov's Model Status in Patients Not Receiving and Receiving Sunitinib as $1^{\text {st }}$ Line Therapy

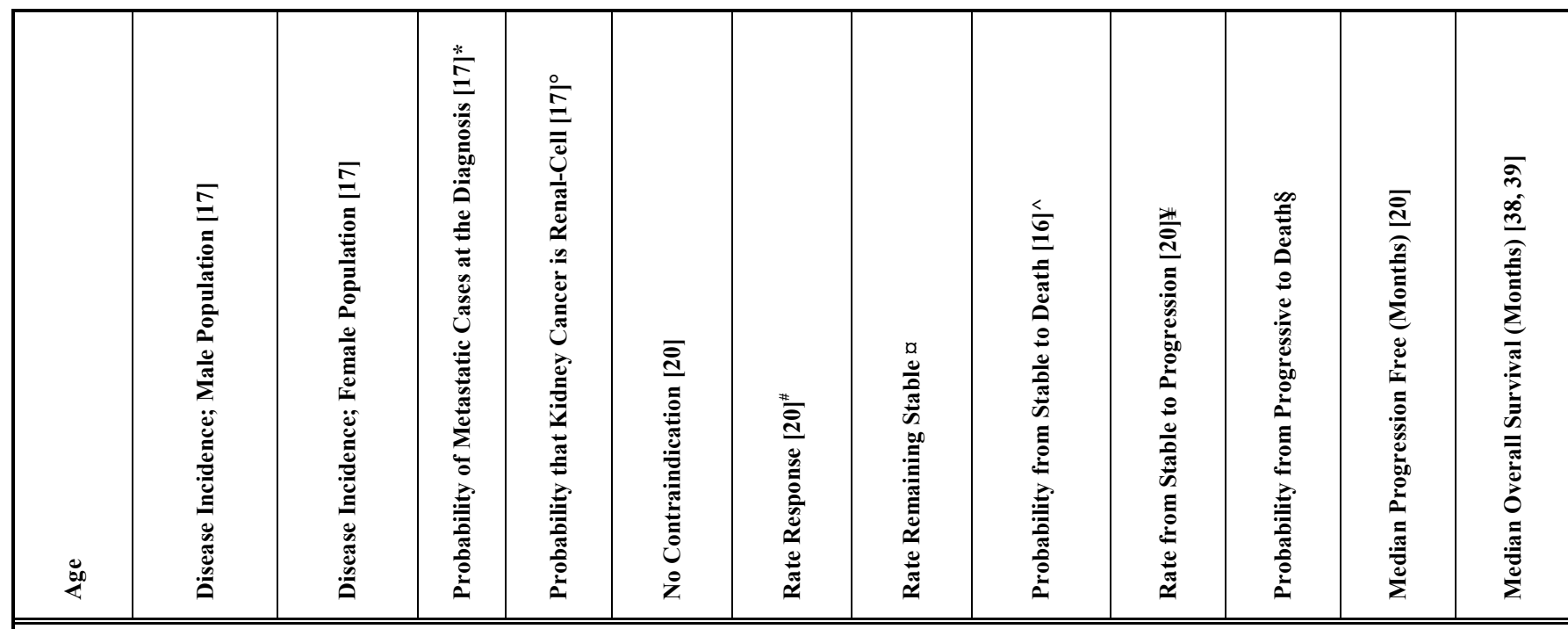

Patients Not Receiving Sunitinib as $1^{\text {st }}$ Line Therapy

\begin{tabular}{|c|c|c|c|c|c|c|c|c|c|c|c|c|}
\hline $0-24$ & 0.0000072 & 0.0000134 & 0.30 & 0.80 & 0.92 & 0.06 & 0.49 & 0.0006761 & 0.45 & 0.45 & 5 & 21.8 \\
\hline $25-49$ & 0.0000686 & 0.0000312 & 0.30 & 0.80 & 0.92 & 0.06 & 0.49 & 0.0008002 & 0.45 & 0.45 & 5 & 21.8 \\
\hline $50-74$ & 0.000695 & 0.000266 & 0.30 & 0.80 & 0.92 & 0.06 & 0.49 & 0.0085 & 0.45 & 0.45 & 5 & 21.8 \\
\hline$\geq 75$ & 0.001311 & 0.0005166 & 0.30 & 0.80 & 0.92 & 0.06 & 0.49 & 0.011 & 0.45 & 0.45 & 5 & 21.8 \\
\hline
\end{tabular}

Patients Receiving Sunitinib as 1st Line Therapy

\begin{tabular}{|c|c|c|c|c|c|c|c|c|c|c|c|c|}
\hline $0-24$ & 0.0000072 & 0.0000134 & 0.30 & 0.80 & 0.87 & 0.31 & 0.48 & 0.0006761 & 0.21 & 0.45 & 11 & 21.8 \\
\hline $25-49$ & 0.0000686 & 0.0000312 & 0.30 & 0.80 & 0.87 & 0.31 & 0.48 & 0.0008002 & 0.21 & 0.45 & 11 & 21.8 \\
\hline $50-74$ & 0.000695 & 0.000266 & 0.30 & 0.80 & 0.87 & 0.31 & 0.48 & 0.0085 & 0.21 & 0.45 & 11 & 21.8 \\
\hline$\geq 75$ & 0.001311 & 0.0005166 & 0.30 & 0.80 & 0.87 & 0.31 & 0.48 & 0.011 & 0.21 & 0.45 & 11 & 21.8 \\
\hline
\end{tabular}

*Defined as the probability to present RCC at a metastatic stage at diagnosis. Probabilities were derived from researched literature.

${ }^{\circ}$ Defined as the probability to present the renal-cell form among all RCC. Probabilities were derived from researched literature.

\#Defined as the rate of patient whose treatment showed positive effect on disease regression.

Defined as the rate of patients whose treatment showed no effect.

^Probability for the patient to switch from a "Stable State" to clinical "Death" in Markov model.

$¥$ Defined as the rate of patients whose treatment showed no effect and a progression of the disease.

§Probability for the patient to switch from "Progressive State" to "Death" in Markov model.

disease", and "Dead". Patients start in the state "Stable disease" where they receive treatment. Patients could then respond to the therapy and remain in the "stable state" or move to a different state when the therapy failed "Progressive disease" or to the state "Dead". Patients in the "Progressive State" who were responding to the therapy, could remain in the same state, or instead switch to the "Death state". Death due to colorectal cancer is only possible for patients in the state "Progressive disease", otherwise the transition to "Dead" is due to other causes. The reference population mimics the distribution of the Veneto population, assuming a median drug dosage for a person of 60 kilograms.

The Markov model structure followed a conventional design in which patients were followed from first-line treatment until death, in 6-week cycles. Patients were assumed to receive active treatment until an assessment of tumor progression was confirmed. Transition probabilities (reflecting the 6-month cycle length) for sorafenib and sunitinib and for people receiving only chemotherapy were derived from major published studies [19-24], necessary for the drug approval of Food and Drug Administration (FDA) and European Medicines Agency (EMA), and institutionalderived data from IOV [17]. Monthly transition probabilities were determined from first year clinical probabilities, using the following formula:

$P=1-e^{-r t}$

where $P$ is the probability of the event, e is the natural logarithm, $r$ is the rate, and $t$ is the time interval [25]. A time period of three years was considered adequate to assess the economic impact of sunitinib and sorafenib. The costs were related to the cost of drug for a full cycle treatment of 6 months. Three scenarios were simulated in order to determine the impact on $\mathrm{mRCC}$ population. The first one where patients were receiving sunitinib as $1^{\text {st }}$ line treatment, while in the second one they were receiving other chemotherapy drugs chemotherapeutics. The third model considered patients treated with sorafenib as $2^{\text {nd }}$ line agent, after receiving a $1^{\text {st }}$ line treatment of sunitinib. 


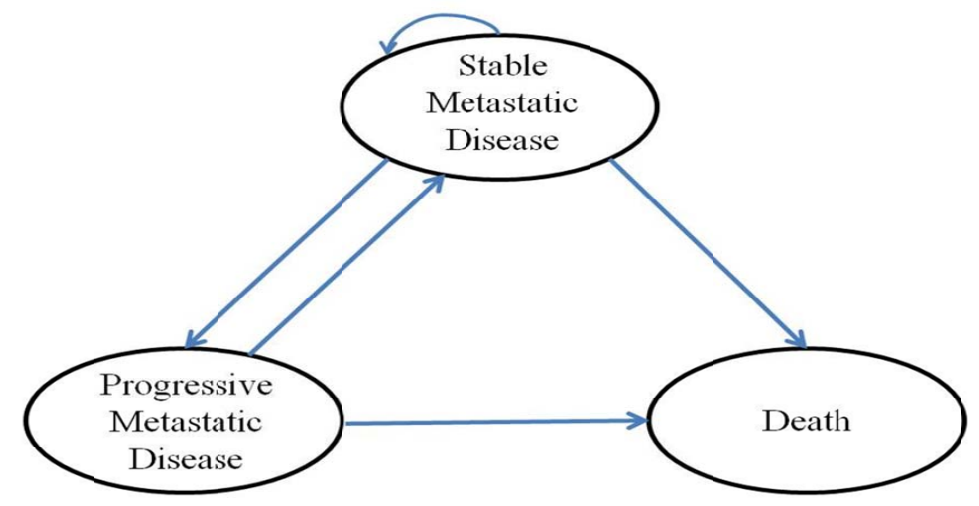

Fig. (1). Markov model*.

*Markov state decision model was built considering transition probabilities from three different states, and by comparing the expected deaths and the monthly survival rates in treatment and no-treatment groups. This indicator has already been proven to be valid tool to for costs considerations12. It consists of 3 different states: "Stable disease" (the status of a patient receiving the therapy), "Progressive disease" (the status of a patient whose therapy was ineffective or whose conditions worsened), and "Dead". The Markov model structure followed a conventional design in which patients were followed from first-line treatment until death, in 6-week cycles. Transition probabilities (reflecting the 6-month cycle length) for sorafenib and sunitinib and for people receiving only chemotherapy were derived from major published studies.

Table 3. Incidences and Probabilities of Transition Among Markov's Model Status in Patients Receiving Sorafenib as $2^{\text {nd }}$ Line Therapy

\begin{tabular}{|c|c|c|c|c|c|c|c|c|c|c|c|c|c|c|}
\hline$\stackrel{80}{Z}$ & 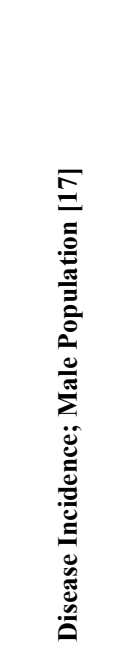 & 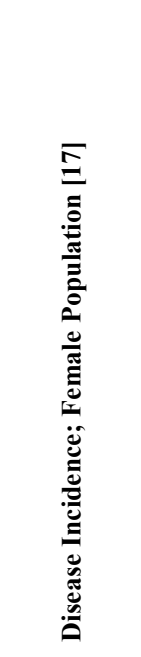 & 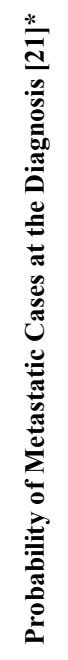 & 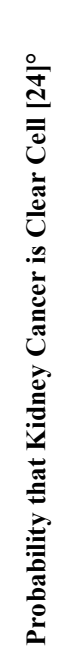 & 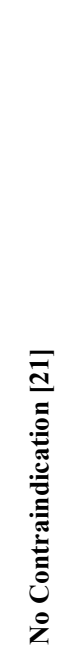 & 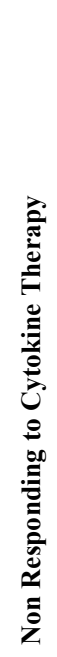 & 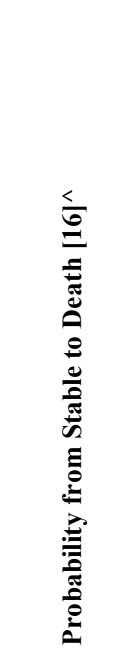 & 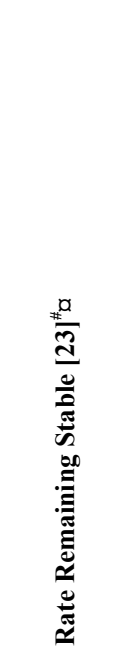 & 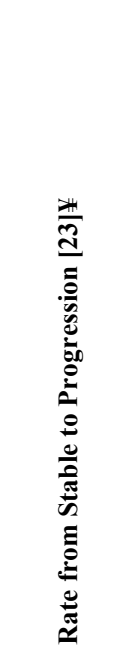 & 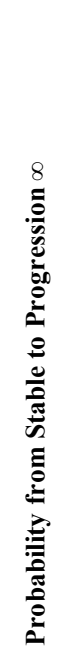 & 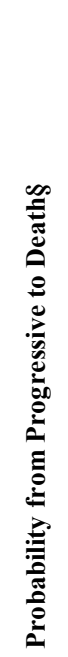 & 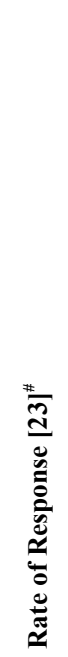 & 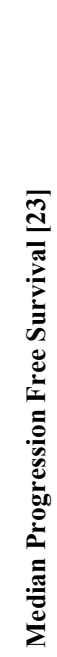 & 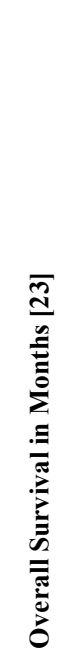 \\
\hline $0-24$ & 0.0000072 & 0.0000134 & 0.30 & 0.22 & 0.87 & 0.8 & 0.0006761 & $0.70-0.78$ & $0.10-0.16$ & 0.14 & 0.38 & 0.10 & 5.5 & 19.3 \\
\hline $25-49$ & 0.0000686 & 0.0000312 & 0.30 & 0.22 & 0.87 & 0.8 & 0.0008002 & $0.70-0.78$ & $0.10-0.16$ & 0.14 & 0.38 & 0.10 & 5.5 & 19.3 \\
\hline $50-74$ & 0.000695 & 0.000266 & 0.30 & 0.22 & 0.87 & 0.8 & 0.0085 & $0.70-0.78$ & $0.10-0.16$ & 0.14 & 0.38 & 0.10 & 5.5 & 19.3 \\
\hline$\geq 75$ & 0.001311 & 0.0005166 & 0.30 & 0.22 & 0.87 & 0.8 & 0.011 & $0.70-0.78$ & $0.10-0.16$ & 0.14 & 0.38 & 0.10 & 5.5 & 19.3 \\
\hline
\end{tabular}

*Defined as the probability to present RCC at a metastatic stage at diagnosis. Probabilities were derived from researched literature.

${ }^{\circ}$ Defined as the probability to present the renal-cell form among all RCC. Probabilities were derived from researched literature.

\#Defined as the rate of patient whose treatment showed positive effect on disease regression.

aDefined as the rate of patients whose treatment showed no effect.

^Probability for the patient to switch from a "Stable State" to clinical "Death" in Markov model.

$¥ D$ fined as the rate of patients whose treatment showed no effect and a progression of the disease.

$\infty$ Probability for the patient to switch from a "Progressive state" to clinical "Death" as calculated through Markov model.

§Probability for the patient to switch from "Progressive State" to "Death" in Markov model.

\section{Simulations}

A micro-simulation approach has been used as the main setting for the analysis. All quantities described above have been implemented in the stochastic simulation model as expected values of suitable probability functions. More in detail, for discrete random variables (e.g.: number of people incident for RCC), a binomial model has been used (e.g.: sampling from the Veneto population with probability equal 
to the age-specific incidence rate). For continuous random variables (e.g.: weight of patients for drug dosage administration), including costs, a Kumaraswamy distribution, which is a very flexible both symmetric and asymmetric two-parameters distribution, has been used [26]. Thus, 10000 Monte Carlo runs have been performed, deriving the empirical distributions of the target quantities of interest (e.g.: cost of care), for which selected summary measures have been computed (e.g.: mean, $5^{\text {th }}$ and $95^{\text {th }}$ percentile, to be used as $90 \%$ credibility intervals for inferential purposes). All estimated quantities are reported along with $90 \%$ credibility intervals. Software used for simulations was the VOSE Model Risk analyzer [27].

\section{RESULTS}

The impact of multitargeted TKIs was evaluated considering $1^{\text {st }}$ and $2^{\text {nd }}$ line treatment in for a full period of 3 years. The impact of sorafenib was considered as added to $1^{\text {st }}$ line therapy sunitinib in all those patients that underwent a transition from stable condition to progressive condition. All data are reported with a $90 \%$ CI.

Results in Table 4 show the impact of sunitinib and sorafenib treatment in all eligible patients. From the initial cohort of 357 patients eligible for sunitinib treatment, stable ones (139) were considered in order to evaluate the impact of the multitargeted agent on overall progression of the disease. Results showed that a smaller portion of patients receiving sunitinib transited from a stable to a progressive state, with respect to the patients who were not receiving sunitinib. When considering sorafenib impact, progression within the first 6 months was seen in the $33 \%$ of patients, whilst the rates of death transitions were achieved $70 \%$ within the first 2 years.
Costs of treatment are presented in Table 5. Sunitinib costs are measured as cumulative costs, considering all patients receiving sunitinib as $1^{\text {st }}$ line treatment in a time frame of three years. The cost of 6 months treatment with sunitinib reached a median value of $2532666 €$, increasing till $3607807 €$ as cumulative amount at 12 months. Costs after the $1^{\text {st }}$ year flattened around the same figure $(3800000 €)$ due to the transition towards death or second line treatments. When evaluating sorafenib costs, data were added to $1^{\text {st }}$ line treatment, in order to outline the full expenses.

\section{DISCUSSION}

Systemic treatment of advanced and metastatic RCC using immunotherapy Interferon-alpha (INF- $\alpha$ ) and Interleuchin-2 (IL-2) was effective only in a minority of patients and was accompanied by substantial toxicity [28] but since December 2005 a series of targeted agents with significantly higher specificity for particular cancer-related pathways, has been approved for the treatment of mRCC, including the two multi-targeted tyrosine kinase inhibitors (TKIs) sunitinib and sorafenib [29]. Based on the molecular pathogenesis of clear cell RCC and excellent preclinical research, the VEGF pathway was exploited as target for drug development. The TKIs sorafenib and sunitinib offered improved outcomes for patients with mRCC [30]. Sunitinib has emerged as the standard of care for treatment-naïve mRCC patients. EMA authorized sorafenib for second-line therapy after cytokine failure, or for first-line therapy in patients unsuitable for cytokines [31]. Moreover sorafenib is a Raff kinase inhibitor that directly suppresses tumor proliferation [32].

The economic burden of mRCC has not been sufficiently reported in the literature, although estimates can be derived from what has been reported for non-metastatic form of RCC

Table 4. Impact of Multitargeted Tyrosine Kinase Inhibitors Use on Overall Survival and Progression of mRCC Patients of Veneto's Cohort. All Data are Presented with a 90\% Credibility Interval Showed in Brackets (C.I.)

\begin{tabular}{|c|c|c|c|}
\hline & $\begin{array}{c}\text { Pts Receiveing Sunitinib as 1st } \\
\text { Line Treatment }\end{array}$ & $\begin{array}{c}\text { Pts Not Receiveing Sunitinib as } \\
\text { 1st Line Treatment }\end{array}$ & $\begin{array}{l}\text { Pts Receiveing Sorafenib } \\
\text { as 2nd Line Treatment }\end{array}$ \\
\hline Eligible at the beginning & 357 & 377 & Not applicable \\
\hline Stable at the beginning & 139 & 150 & Not applicable \\
\hline Eligible in 36 months & Not applicable & Not applicable & 30 \\
\hline in Progression by the 6th month & $81(65 ; 97)$ & $129(110 ; 150)$ & $5(2 ; 9)$ \\
\hline in Progression by the 12 th month & $31(22 ; 41)$ & $74(60 ; 90)$ & $7(3 ; 12)$ \\
\hline in Progression by the 18 th month & $5(2 ; 9)$ & $25(17,34)$ & $2(0 ; 5)$ \\
\hline in Progression by the 24th month & $0(0 ; 1)$ & $3(0 ; 6)$ & $0(0 ; 1)$ \\
\hline in Progression by the 30 th month & $0(0 ; 0)$ & $0(0 ; 0)$ & $0(0 ; 0)$ \\
\hline in Progression by the 36 th month & $0(0 ; 0)$ & $0(0 ; 0)$ & $0(0 ; 0)$ \\
\hline Dead by the 6th month & $136(116 ; 158)$ & $97(81 ; 114)$ & $6(2 ; 10)$ \\
\hline Dead by the 12 th month & $266(235 ; 268)$ & $216(189 ; 244)$ & $10(5 ; 15)$ \\
\hline Dead by the 18th month & $341(305 ; 308)$ & $323(289 ; 360)$ & $17(10 ; 24)$ \\
\hline Dead by the 24 th month & $356(319 ; 396)$ & $371(333 ; 411)$ & $21(14 ; 30)$ \\
\hline Dead by the 30 th month & $356(319 ; 396)$ & $377(338 ; 417)$ & $22(15 ; 31)$ \\
\hline Dead by the 36 th month & $356(319 ; 396)$ & $377(338 ; 417)$ & $22(15 ; 31)$ \\
\hline
\end{tabular}


Table 5. Cost Impact of Sunitinib and Sorafenib Use of Veneto mRCC Cohort. All Data are Expressed in Euros, with a 90\% Credibility Interval Showed in Brackets (C.I.)

\begin{tabular}{|c|c|c|}
\hline & Sunitinib & Sunitinib + Sorafenib \\
\hline \hline Cumulative cost at 6th month & $2532666(893777 ; 3434238)$ & $2633573(1039632 ; 3539720)$ \\
\hline Cumulative cost at 12th month & $3607807(1279422 ; 4897872)$ & $3800899(1545855 ; 5100104)$ \\
\hline Cumulative cost at 18th month & $3790506(1358370 ; 5154840)$ & $4056495(1697715 ; 5429808)$ \\
\hline Cumulative cost at 24th month & $3795590(1359918 ; 5157936)$ & $4079500(1722720 ; 5462528)$ \\
\hline Cumulative cost at 30th month & $3795599(1359918 ; 5157936)$ & $4080409(1722720 ; 5462528)$ \\
\hline Cumulative cost at 36th month & $3795599(1359918 ; 5157936)$ & $4080411(1722720 ; 5462528)$ \\
\hline
\end{tabular}

and from kidney cancer in general. Taken the large use that these drugs have rapidly gained, an economical evaluation of their impact needed to be performed, due to the high costs of these TKIs.

Considering the Italian background, the Italian public health system (Servizio Sanitario Nazionale, or SSN) covers all citizens and legal foreign residents. In the $\mathrm{SSN}$, prescription drugs are divided into three groups according to clinical effectiveness and, in part, cost-effectiveness; the SSN covers the first tier in all cases and the second tier only in hospitals, but does not cover the third tier. In 2008 regions were compelled to be financed through standard costs [33] and the 20 Italian regions have responsibility for the organization and delivery of health services, while the central government mostly having the taxes revenue. Hospital pharmaceutical spending has also been under control since the institution of the SSN. In fact regions can set up their own regional hospital formularies based on the national therapeutic formulary, in order to monitor and rationalize drugs consumption. Drugs included in class $\mathrm{H}$ are exclusively given in hospital, selected on the basis of certain types of pathologies and side effects in relation to benefits. All the costs of class $\mathrm{H}$ drugs are borne from the hospital. Most anti neoplastic agents, as TKIs, are examples of class $\mathrm{H}$ drugs.

As shown from our results the costs of the first 6 months therapy with sunitinib have a very high impact on public health expenses in the Regione Veneto. $2^{\text {nd }}$ line treatment with sorafenib instead increased overall expenses of a reduced proportion, due to the small proportion of patients undergoing this treatment and the relative inferior cost of the drug. Despite overall survival after 3 years of diagnosis appeared to be null, sunitinib treated patients may stay in a stable condition longer than those not that would be treated with a multitargeted agent.

Similar results could be registered also in other nations, being a substantial economic burden to the healthcare systems of nations worldwide. The economic burden is particularly relevant to public payers in the US, as almost $46 \%$ of renal cancer patients are covered by Medicare [34]. Recently the UK clinical watchdog has proposed rejecting four drugs, among those sunitinib and sorafenib, for use on the NHS for advanced renal cancer, declaring them clinically effective but not good value for money [35]. As for the Italian costs, the average cost treatment was about $€ 30600$ a year for each patient.
In the case of metastatic cancer, treatment can be recommended even without an improvement in survival, if it improves quality of life [36]. This is especially important for mRCC patients, whose prognosis for long term survival may be poor and where the central goal of treatment is to optimize quality and quantity of life [37]. Several studies have been published on the efficacy of this treatment in Metastatic RCC in Veneto region [17, 19]. Venturini presented Veneto's cases in comparison with other published randomized clinical trials (RCT) [17]. Data regarding outcome showed that $38.1 \%$ of patients experienced disease progression or death in the sorafenib trial versus $58 \%$ in real life while this proportion was $21 \%$ in the sunitinib trial versus $46 \%$ in the register. Positive results were found also in Brunello's research held on elderly patients [19]. At a median follow-up of 27.1 months, the median observed survival was 18.3 months and the median PFS was 13.6 months.

From the results of our simulated model on costs borne by the SSN and on the basis of the results of their use on Veneto's patients for the treatment of patients with $\mathrm{mRCC}$, we can conclude that they are effective on the progression of the disease the greatest impact being the cost for the $1^{\text {st }}$ line pharmacological treatment.

\section{CONFLICT OF INTEREST}

The authors certify that there is no conflict of interest with any organization regarding the material discussed in the manuscript.

\section{ACKNOWLEDGEMENTS}

This research was partially funded by an unrestricted grant of the University of Padova, Progetti di Ateneo 2009, (Code CPDA093183/09, "Modello per la valutazione dell'impatto economico, sociale e di salute derivante dall'utilizzo dei nuovi farmaci oncologici nella regione Veneto").

\section{REFERENCES}

[1] Ferlay, J.; Shin, H. R.; Bray, F.; Forman, D.; Mathers, C.; Parkin, D. M. Estimates of worldwide burden of cancer in 2008: GLOBOCAN 2008. Int. J. Cancer, 2011, 127 (12), 2893-2917.

[2] Levi, F.; Ferlay, J.; Galeone, C.; Lucchini, F.; Negri, E.; Boyle, P.; $\mathrm{La}$ Vecchia, C. The changing pattern of kidney cancer incidence and mortality in Europe. BJU. Int., 2008., 101 (8), 949-958.

[3] Dal Maso, L.; De Angelis, R.; Guzzinati, S. [AIRTUM numbers: 200,000 young Italians live with cancer]. Epidemiol. Prev., 2011. $35(1), 59$. 
[4] Istituto Superiore di Sanità: Centro Nazionale di Epidemiologia, S. e. P. d. S. d. S. La mortalità per causa in Italia. Available at: http://www.iss.it/site/mortalita/.

[5] Bosetti, C.; Bianchi, C.; Negri, E.; La Vecchia, C. Estimates of the incidence and prevalence of renal cell carcinoma in Italy in 2002 and projections for the years 2007 and 2012. Tumori, 2009, 95 (2), $142-145$.

[6] Wu, B.; Dong, B.; Xu, Y.; Zhang, Q.; Shen, J.; Chen, H.; Xue, W. Economic evaluation of first-line treatments for metastatic renal cell carcinoma: a cost-effectiveness analysis in a health resourcelimited setting. PLOS. ONE, 2012, 7 (3), e32530.

[7] Gupta, K.; Miller, J. D.; Li, J. Z.; Russell, M. W.; Charbonneau, C. Epidemiologic and socioeconomic burden of metastatic renal cell carcinoma (mRCC): a literature review. Cancer. Treat. Rev, 2008, 34 (3), 193-205.

[8] Schrader, A. J.; Varga, Z.; Hegele, A.; Pfoertner, S.; Olbert, P.; Hofmann, R. Second-line strategies for metastatic renal cell carcinoma: classics and novel approaches. J. Cancer. Res. Clin. Oncol., 2006, 132 (3), 137-149.

[9] Figlin, R.; Sternberg, C.; Wood, C. G. Novel Agents and Approaches for Advanced Renal Cell Carcinoma. J. Urol., 2012, 188 (3), 707-715.

[10] Mena, A. C.; Pulido, E. G.; Guillen-Ponce, C. Understanding the molecular-based mechanism of action of the tyrosine kinase inhibitor: sunitinib. Anticancer Drugs, 2010, 21 Suppl 1, S3-11.

[11] Wood, L., Sunitinib malate for the treatment of renal cell carcinoma. Expert. Opin. Pharmacother., 2012, 13 (9), 1323-1336.

[12] Le Tourneau, C.; Raymond, E.; Faivre, S. Sunitinib: a novel tyrosine kinase inhibitor. A brief review of its therapeutic potential in the treatment of renal carcinoma and gastrointestinal stromal tumors (GIST). Ther. Clin. Risk Manag., 2007, 3 (2), 341-348.

[13] Gotink, K. J.; Verheul, H. M. Anti-angiogenic tyrosine kinase inhibitors: what is their mechanism of action? Angiogenesis, 2010, 13 (1), 1-14

[14] Fournier, C.; Tisman, G. Sorafenib-associated remission of psoriasis in hypernephroma: case report. Dermatol. Online J., 2010, 16 (2), 17.

[15] Baselga, J.; Segalla, J. G.; Roche, H.; Del Giglio, A.; Pinczowski, H.; Ciruelos, E. M.; Filho, S. C.; Gomez, P.; Van Eyll, B.; Bermejo, B.; Llombart, A.; Garicochea, B.; Duran, M. A.; Hoff, P. M.; Espie, M.; de Moraes, A. A.; Ribeiro, R. A.; Mathias, C.; Gil Gil, M.; Ojeda, B.; Morales, J.; Kwon Ro, S.; Li, S.; Costa, F. Sorafenib in combination with capecitabine: an oral regimen for patients with HER2-negative locally advanced or metastatic breast cancer. J. Clin. Oncol., 2012, 30 (13), 1484-1491.

[16] Marchioli, R.; Marfisi, R. M.; Carinci, F.; Tognoni, G. Metaanalysis, clinical trials, and transferability of research results into practice. The case of cholesterol-lowering interventions in the secondary prevention of coronary heart disease. Arch Intern. Med, 1996, 156 (11), 1158-1172.

[17] Venturini, F.; Costa, E.; Maimone, P.; Scroccaro, G. Transferability of clinical trials results to clinical practice: the example of new drugs for renal cell carcinoma. Eur. J. Hosp. Pharm. Sci. Pract., 2012, 19 (2), 257.

[18] Lidgren, M.; Wilking, N.; Jonsson, B.; Rehnberg, C. Costeffectiveness of HER2 testing and trastuzumab therapy for metastatic breast cancer. Acta. Oncol., 2008, 47 (6), 1018-1028.

[19] Brunello, A.; Basso, U.; Sacco, C.; Sava, T.; De Vivo, R.; Camerini, A.; Barile, C.; Roma, A.; Maruzzo, M.; Falci, C.; Zagonel, V. Safety and activity of sunitinib in elderly patients ( $>=70$ years) with metastatic renal cell carcinoma: a multicenter study. Ann. Oncol., 2012. 24 (2), 336-342.

[20] Motzer, R. J.; Hutson, T. E.; Tomczak, P.; Michaelson, M. D.; Bukowski, R. M.; Rixe, O.; Oudard, S.; Negrier, S.; Szczylik, C.; Kim, S. T.; Chen, I.; Bycott, P. W.; Baum, C. M.; Figlin, R. A. Sunitinib versus interferon alfa in metastatic renal-cell carcinoma. N. Engl. J. Med, 2007, 356 (2), 115-124.
[21] Motzer, R. J.; Rini, B. I.; Bukowski, R. M.; Curti, B. D.; George, D. J.; Hudes, G. R.; Redman, B. G.; Margolin, K. A.; Merchan, J. R.; Wilding, G.; Ginsberg, M. S.; Bacik, J.; Kim, S. T.; Baum, C. M.; Michaelson, M. D, Sunitinib in patients with metastatic renal cell carcinoma. JAMA, 2006, 295 (21), 2516-2524.

[22] Mulders, P. F. Renal cell carcinoma. World. J. Urol., 2008, 26 (2), 113.

[23] Escudier, B.; Eisen, T.; Stadler, W. M.; Szczylik, C.; Oudard, S.; Siebels, M.; Negrier, S.; Chevreau, C.; Solska, E.; Desai, A. A.; Rolland, F.; Demkow, T.; Hutson, T. E.; Gore, M.; Freeman, S.; Schwartz, B.; Shan, M.; Simantov, R.; Bukowski, R. M. Sorafenib in advanced clear-cell renal-cell carcinoma. N. Engl. J. Med., 2007, $356(2), 125-134$.

[24] Heger, J.; Euler, G. iNOS--another cardiac target of calcineurin. Cardiovasc. Res., 2006, 71 (4), 612-614.

[25] Drummond, M. F.; Sculpher, M. J.; Torrance, W. G.; O'Brien, B. J.; Stoddart, G. L. Methods. for the economic. Evaluation. of health. care programmes, $3^{\text {rd }}$ ed.; Oxford University Press: Oxford., New York, 2005; p. 379.

[26] Kumaraswamy, P. A generalized probability density function for double-bounded random processes. J. Hydrol., 1980, 46 (1-2), 7988.

[27] Van Hauwermeiren, M.; Vose, D.; Vanden Bossche, S. A Compendium of Distributions. Software, V., Ed. Ghent, Belgium, 2012. Available at www.vosesoftware.com [Accessed: $29^{\text {th }}$ May 2012].

[28] McDermott, D. F. Immunotherapy of metastatic renal cell carcinoma. Cancer, 2009, 115 [10 Suppl], 2298-2305.

[29] Bukowski, R. M., Tyrosine kinase inhibitors in advanced renal cell carcinoma: the evolving treatment paradigm. Clin. Genitourin. Cancer, 2009, 7 (1), 9-10.

[30] Hiles, J. J.; Kolesar, J. M. Role of sunitinib and sorafenib in the treatment of metastatic renal cell carcinoma. Am. J. Health. Syst. Pharm, 2008, 65 (2), 123-131.

[31] Nexavar EMEA label. Available at: http://www.ema.europa.eu/ema/

[32] Wilhelm, S. M.; Carter, C.; Tang, L.; Wilkie, D.; McNabola, A.; Rong, H.; Chen, C.; Zhang, X.; Vincent, P.; McHugh, M.; Cao, Y.; Shujath, J.; Gawlak, S.; Eveleigh, D.; Rowley, B.; Liu, L.; Adnane, L.; Lynch, M.; Auclair, D.; Taylor, I.; Gedrich, R.; Voznesensky, A.; Riedl, B.; Post, L. E.; Bollag, G.; Trail, P. A. BAY 43-9006 exhibits broad spectrum oral antitumor activity and targets the $\mathrm{RAF} / \mathrm{MEK} / \mathrm{ERK}$ pathway and receptor tyrosine kinases involved in tumor progression and angiogenesis. Cancer. Res., 2004, 64 (19), 7099-7109.

[33] Maio, V.; Manzoli, L. The Italian Health Care System:W.H.O.ranking versus public perception. Pharm. Ther., 2002, 27 (6), 301-308.

[34] Allareddy, V.; Konety, B. Inpatient costs for bladder, kidney, and prostate cancers in the year 2002. A study using the NIS sample. American Urological Association Annual Meeting, USA, 2006.

[35] O'Dowd, A. Watchdog set to reject four drugs for kidney cancer on the NHS. BMJ, 2008, 337, a1262.

[36] Outcomes of cancer treatment for technology assessment and cancer treatment guidelines. American Society of Clinical Oncology. J. Clin. Oncol., 1996, 14 (2), 671-9.

[37] Litwin, M. S.; Fine, J. T.; Dorey, F.; Figlin, R. A.; Belldegrun, A. S. Health related quality of life outcomes in patients treated for metastatic kidney cancer: a pilot study. J. Urol., 1997, 157 (5), 1608-16012.

[38] Motzer, R. J.; Hutson, T. E.; Tomczak, P.; Michaelson, M. D.; Bukowski, R. M.; Oudard, S.; Negrier, S.; Szczylik, C.; Pili, R.; Bjarnason, G. A.; Garcia-del-Muro, X.; Sosman, J. A.; Solska, E.; Wilding, G.; Thompson, J. A.; Kim, S. T.; Chen, I.; Huang, X.; Figlin, R. A. Overall survival and updated results for sunitinib compared with interferon alfa in patients with metastatic renal cell carcinoma. J. Clin. Oncol., 2009, 27 (22), 3584-3590.

[39] Motzer, R. J.; Molina, A. M. Targeting renal cell carcinoma. J. Clin. Oncol., 2009, 27 (20), 3274-3276. 